Relations industrielles

Industrial Relations

\title{
Un évêque social
}

\section{Georges-Henri Lévesque}

Volume 4, numéro 1, septembre 1948

URI : https://id.erudit.org/iderudit/1023421ar

DOI : https://doi.org/10.7202/1023421ar

Aller au sommaire du numéro

Éditeur(s)

Département des relations industrielles de l’Université Laval

ISSN

0034-379X (imprimé)

1703-8138 (numérique)

Découvrir la revue

Citer cet article

Lévesque, G.-H. (1948). Un évêque social. Relations industrielles / Industrial Relations, 4(1), 1-1. https://doi.org/10.7202/1023421ar

Tous droits réservés @ C Département des relations industrielles de l’Université Laval, 1948
Ce document est protégé par la loi sur le droit d'auteur. L'utilisation des services d'Érudit (y compris la reproduction) est assujettie à sa politique d'utilisation que vous pouvez consulter en ligne.

https://apropos.erudit.org/fr/usagers/politique-dutilisation/ 


\section{Bulletin des relations industrielles}

Volume 4, numéro 1

QUÉBEC

Septembre 1948

Publié par le

Département des relations industrielles, Faculté des sciences sociales, Université Laval.

Georges-Hentu Lévesque, o.p., doyen Gérard Tremblay, directeur GERARD DION, sous-directeur Jean Gagne, secrétaire

Charles Bélanger, administrateur

Le Bulletin paraît mensuellement de septembre à juin (dix numéros par année). Abonnement annuel: Canada: $\$ 1.50$; étranger: $\$ 2.00$. Vingt-cinq cents le numéro.

\section{Adressez toute correspondance au secrétaire de rédaction GÉrard Dion}

2, rue de l'Université, Québec.

Bulletin des relations industrielles Volume 4, numero 1 septembre 1948

\section{Sommaire}

Un évêque social

T.R.P. Georges-Henri LÉvesQue, o.p. 1

In Memoriam: Egbert Munzer

Léon Dion.

La Confédération des travailleurs catholiques du Canada

Alfred Charpentier

Le Congrès canadien du travail

Eugene Forsey.

Le droit des travailleurs de participer activement a la vie de l'entreprise

Mgr P.-Pavan.. ..

\section{Collaborateurs}

Charpentier, Alfred, Diplômé en sciences sociales (Université de Montréal), directeur, Service de recherches et d'éducation, Confédération des travailleurs catholiques du Canada Inc.

Dion, Léon, B.A., M.Sc.Soc., professeur, Faculté des sciences sociales.

Forsey, Eugene, B.A., M.A., Ph.D., directeur des recherches, Congrès canadien du travail.

LÉvesque, T.R.P. Georges-Henri, o.p. doyen, Faculté des sciences sociales.

Autorisé comme envoi postal de deuxième classe, ministère des postes, Ottawa, Canada.

\section{UN ÉVÊQUE SOCIAL}

Le 29 juin dernier, en la fête des saints apôtres Pierre et Paul, avait lieu la consécration épiscopale de Son Excellence Monseigneụr Charles-Omer Garant, évêque auxiliaire de Québec.

Ce fut aussi un jour de fête pour tout le monde social québecois et en particulier pour la Faculté des sciences sociales de Laval dont il fut un des pionniers et en qui elle a sans cesse trouvé, depuis ses origines, un judicieux conseiller et un ferme appui dans les oeuvres qu'elle a eu à accomplir comme aussi dans les difficultés qu'elle a eu à traverser. Monseigneur Garant a d'ailleurs fait partie du corps professoral et du bureau de direction de notre Faculté jusqu'au moment où le surcroît de travail que lui imposaient ses fonctions à la Faculté de théologie vint nous l'enlever.

Mais il est toujours resté ce que son amour de la justice et sa grande charité sacerdotale lont fait: un apôtre social. Monseigneur Garant, c'est l'homme qui s'est dévoué sans compter à la cause de lorganisation professionnelle chez nous. Pénétré de l'esprit des encycliques sociales et attiré par le bien qu'il voyait à réaliser dans notre société il s'est consacré à la tàche difficile et souvent si ingrate d'inspirer et de construire pour elle des institutions appropriées et susceptibles d'en assurer l'ordre et la paix. Québec lui doit la gloire d'avoir été le grand instigateur du mouvement d'organisation professionnelle patronale chez nous.

Et ce qui est extraordinaire dans l'apostolat de cet homme c'est que tout en éveillant le monde patronal à la conscience de son besoin d'organisation il n'a jamais cessé de lui prêcher également le respect dû aux justes exigences de l'élément ouvrier. C'est là une attitude bien explicable chez Monseigneur Garant, car il est un de ceux qui conçoivent la vie sociale non comme une lutte nécessaire entre des ennemis irréconciliables mais bien comme un laborieux et bienfaisant effort de fraternité entre des hommes rachetés par l'amour.

Pouvait-il en être autrement d'ailleurs de celui qui devait un jour, en recevant le plénitude du sacerdoce, choisir pour devise «in justitia et caritate », deux mots, ou plutôt deux choses qui sont tout lui-même et toute sa vie.

A notre nouvel et si sympathique évêque auxiliaire il nous fait infiniment plaisir de dire nos chaleureuses félicitations et d'exprimer nos voeux les plus fervents. Est-il seulement besoin d'ajouter qu'il trouvera toujours à «sa » Faculté des sciences sociales toute la collaboration qu'il est en droit d'en attendre et qu'elle sera toujours fière et très heureusé de lui donner? 